\title{
Optimizing the Respiratory Pump: Harnessing Inspiratory Resistance to Treat Systemic Hypotension
}

\author{
Victor A Convertino PhD, Kathy L Ryan PhD, Caroline A Rickards PhD, Steven L Glorsky MD, \\ Ahamed H Idris MD, Demetris Yannopoulos MD, Anja Metzger PhD and Keith G Lurie MD
}

\author{
Introduction \\ Mechanisms Underlying the Hemodynamic Effectiveness of the \\ Respiratory Pump \\ Effects on Central Hemodynamics \\ Resetting of the Cardiac Baroreflex \\ Patient Tolerance and Response to Acute Central Hypovolemia Induced \\ by Orthostasis \\ Potential Mechanisms of Action: Effects on Pressure Gradients That \\ Determine Tissue Blood Flow \\ Clinical Relevance of the Respiratory Pump \\ Outcomes From Clinical Applications \\ Future Directions \\ Summary
}

We review the physiology and affects of inspiration through a low level of added resistance for the treatment of hypotension. Recent animal and clinical studies demonstrated that one of the body's natural response mechanisms to hypotension is to harness the respiratory pump to increase circulation. That finding is consistent with observations, in the 1960s, about the effect of lowering intrathoracic pressure on key physiological and hemodynamic variables. We describe studies that focused on the fundamental relationship between the generation of negative intrathoracic pressure during inspiration through a low level of resistance created by an impedance threshold device and the physiologic sequelae of a respiratory pump. A decrease in intrathoracic pressure during inspiration through a fixed resistance resulting in a pressure difference of $7 \mathrm{~cm} \mathrm{H}_{2} \mathrm{O}$ has multiple physiological benefits, including: enhanced venous return and cardiac stroke volume, lower intracranial pressure, resetting of the cardiac baroreflex, elevated cerebral blood flow oscillations, increased tissue blood flow/pressure gradient, and maintenance of the integrity of the baroreflexmediated coherence between arterial pressure and sympathetic nerve activity. While breathing has traditionally been thought primarily to provide gas exchange, studies of the mechanisms involved in animals and humans provide the physiological underpinnings for "the other side of breathing": to increase circulation to the heart and brain, especially in the setting of physiological stress. The existing results support the use of the intrathoracic pump to treat clinical conditions associated with hypotension, including orthostatic hypotension, hypotension during and after hemodialysis, hemorrhagic shock, heat stroke, septic shock, and cardiac arrest. Harnessing these fundamental mechanisms that control cardiopulmonary physiology provides new opportunities for respiratory therapists and others who have traditionally focused on ventilation to also help treat serious and often life-threatening circulatory disorders. Key words: hemorrhagic shock; lower-body negative pressure; intrathoracic pressure; impedance threshold device; cardiovascular collapse. [Respir Care 2011;56(6): 846-857. (c) 2011 Daedalus Enterprises] 


\section{Introduction}

The development of severe hypotension associated with failure of adequate compensatory responses to central hypovolemia (ie, hemodynamic decompensation) is a common clinical problem that has plagued trauma and cardiac arrest patients, astronauts, athletes, military personnel, and millions of others with periodic or persistent hypotension worldwide. Continued research related to the mechanism of action of inspiration through a low level of inspiratory resistance on the cardiovascular system has helped to elucidate the physiologic mechanism for utilizing the normal respiratory effort not only for gas exchange but also to increase blood flow to the heart, brain, and other vital organs. This paper is focused on "the other side of breathing": the effects of inspiration that control a wide range of fundamental physiological processes that are part of an innate life-preserving reflex to restore and maintain brain and coronary perfusion in the setting of severe hemodynamic decompensation secondary to hypovolemia. Consider, for example, the "last gasp" in the setting of a dying patient. This primitive reflex lowers intrathoracic pressure, introduces respiratory gas into the lungs, increases venous return to the heart, enhances cardiac stroke volume, and lowers intracranial pressure, thereby improving cerebral perfusion by lowering resistance to forward blood flow. It is no surprise, therefore, that studies have shown that patients in cardiac arrest who gasp or have agonal respira-

Drs Convertino, Ryan, and Glorsky are affiliated with the United States Army Institute of Surgical Research, Fort Sam Houston, Texas. Dr Rickards is affiliated with the University of Texas at San Antonio, San Antonio, Texas. Dr Idris is affiliated with the Departments of Surgery and Emergency Medicine, University of Texas Southwestern Medical Center, Dallas, Texas. Drs Yannopoulos, Metzger, and Lurie are affiliated with the Department of Emergency Medicine, Hennepin County Medical Center, Minneapolis, Minnesota. Drs Metzger and Lurie are also affiliated with Advanced Circulatory Systems, Roseville, Minnesota.

This study was partly supported by the United States Army Medical Research and Materiel Command Combat Casualty Care Research Program, and by Cooperative Research and Development Agreement DAMD17-02-0160 between the United States Army Institute of Surgical Research and Advanced Circulatory Systems.

Drs Metzger and Lurie have disclosed a relationship with Advanced Circulatory Systems. The other authors have disclosed no conflicts of interest.

The opinions and assertions in this paper are the private views of the authors and are not to be construed as reflecting the views of the United States Department of the Army or Department of Defense.

Correspondence: Victor A Convertino PhD, United States Army Institute of Surgical Research, 3698 Chambers Pass, Fort Sam Houston TX 782346315. E-mail: victor.convertino@ amedd.army.mil.

DOI: $10.4187 /$ respcare. 01018

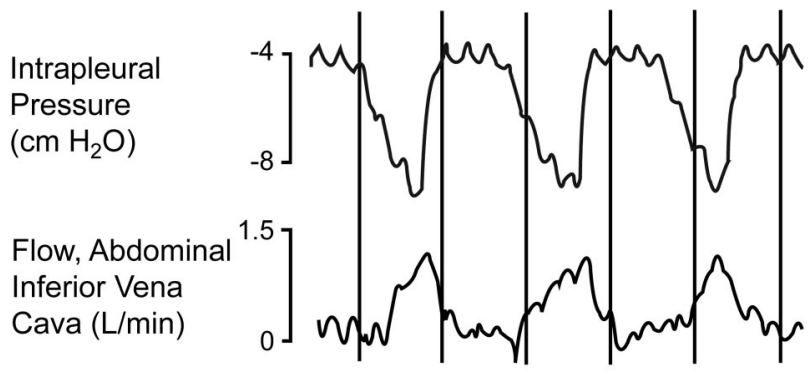

Fig. 1. Relationship between intrathoracic pressure and venous return. (Adapted from Reference 4, with permission.)

tions have a better outcome than those who do not. ${ }^{1-3}$ While some aspects of the "last gasp" have only recently been clarified, it is clear that the generation of negative intrathoracic pressure is a primary mechanical driver behind these multiple benefits. Studies, in 1967, describing the changes in arterial and venous waveforms, demonstrated a fundamental relationship between a reduction in intrathoracic pressure and changes in blood flow back to the heart through the abdominal interior vena cava (Fig. 1). ${ }^{4}$

While this fundamental relationship between inspiratory effort and the enhancement of venous blood was described decades ago, only recently have technologies been developed that exploit this basic physiological process to benefit patients with hypotension and other states of decreased vital organ perfusion. Many of the more recent studies involved the use of an impedance threshold device (ITD) that augments negative intrathoracic pressure each time the intrathoracic pressure is below atmospheric pressure. The ITD is a small disposable plastic valve that can be attached to a face mask or tracheal tube.

The ITD has a spring-loaded diaphragm that requires a threshold "cracking pressure" during inspiration before it opens to allow air flow (Fig. 2). During expiration the diaphragm is pushed outward and the exhaled gas moves out through the ventilation port. The manufacturer's adjustment of the spring constant dictates the level of added resistance. The ITD lowers intrathoracic pressures in a manner analogous to the "last gasp" or a Müller maneuver: inspiration against a closed glottis. Studies have shed light on how to easily use the thoracic pump to augment venous blood flow return, lower intracranial pressure, and regulate cardiopulmonary-cerebral blood flow in spontaneously breathing individuals and in patients in cardiac arrest receiving cardiopulmonary resuscitation (CPR)..$^{5-19}$

\section{Mechanisms Underlying the Hemodynamic Effectiveness of the Respiratory Pump}

\section{Effects on Central Hemodynamics}

The first series of experiments in humans on the mechanism of the respiratory pump focused on the way the 


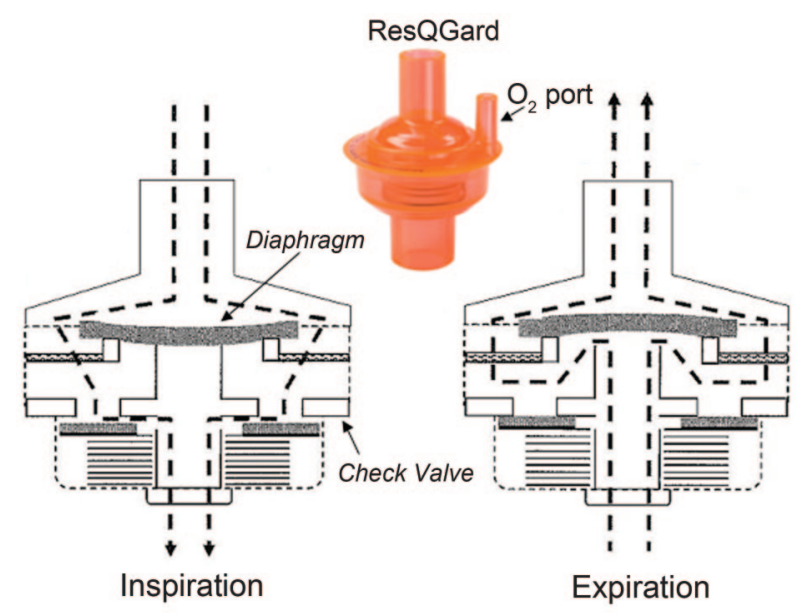

Fig. 2. The ResQGARD impedance threshold device, and diagrams of the air flow through the device during spontaneous inspiration and expiration. Supplemental oxygen can be added at the oxygen port.
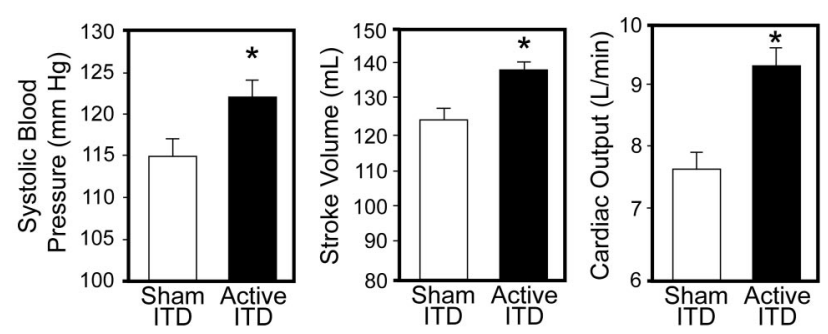

Fig. 3. Systolic blood pressure, stroke volume, and cardiac output in 20 human subjects breathing through an impedance threshold device (ITD, set for a pressure difference of $7 \mathrm{~cm} \mathrm{H}_{2} \mathrm{O}$ ), and a sham ITD. The data bars represent the mean values. The error bars represent standard error values. All the differences are statistically significant. (Adapted from Reference 14.)

body uses its respiratory drive to augment blood pressure and cardiac output, reset the cardiac baroreflex, and altering sympathetic tone associated with the baroreflex. The initial experiments were designed to test the hemodynamics and efficacy of spontaneous breathing through low levels of resistance in resting supine humans. ${ }^{14,15,20}$ Beatto-beat arterial blood pressures, heart rate, respiration, and the stimulus-response relationship of the carotid-cardiac baroreflex were measured in 20 normal subjects in the supine position while they breathed through a face mask with an ITD set at a fixed resistance, resulting in a pressure difference of $7 \mathrm{~cm} \mathrm{H}_{2} \mathrm{O}$ or no resistance (sham ITD). Compared to the sham ITD, the $7 \mathrm{~cm} \mathrm{H}_{2} \mathrm{O}$ active ITD produced an elevated systolic blood pressure that was associated with higher stroke volume and cardiac output (Fig. 3). These initial investigations indicated that the primary mechanism underlying the elevated arterial blood pressure associated with additional negative thoracic pressure is increased venous return, stroke volume, and cardiac output.

\section{Resetting of the Cardiac Baroreflex}

Building upon those results, the next series of studies examined the effect of breathing through a low level of resistance on resetting of the cardiac baroreflex. Inspiration through an ITD, with a pressure difference of $7 \mathrm{~cm} \mathrm{H}_{2} \mathrm{O}$, did not reduce heart rate or alter the cardiac baroreflex sensitivity. ${ }^{15}$ The absence of a reflex-mediated reduction in heart rate with increased systolic blood pressure supported the concept of a resetting of the cardiac baroreflex, such that the reflex relationship between stimulus (arterial blood pressure) and response (RR interval) was shifted to a higher arterial pressure range. ${ }^{15}$ This "resetting" of the cardiac baroreflex provides the physiologic advantage of allowing an increase in heart rate even in the presence of elevated blood pressure, and thus contributes to improved cardiac output.

The ability of the thoracic pump to alter sympathetically mediated baroreflex regulation of blood pressure was demonstrated in an experimental model to simulate progressive hemorrhage in humans, ${ }^{21}$ using lower-body negative pressure, which provides a unique method of systematically reducing venous return and stroke volume (Fig. 4, left panel) until the subject experiences hemodynamic decompensation, defined by a precipitous fall in systolic blood pressure and onset of pre-syncopal symptoms such as grayout, sweating, nausea, or dizziness (see Fig. 4, right panel). With that model, during compensation the stimulus-response relationship between arterial pressure and muscle sympathetic nerve activity oscillations was more tightly coupled to central blood volume reductions, whereas hemodynamic decompensation may reflect uncoupling (ie, reduced coherence) between arterial pressure and muscle sympathetic nerve activity. ${ }^{22}$ The upper 3 panels of Figure 5 show an example of reduced coherence between arterial pressure and muscle sympathetic nerve activity in recordings from a subject who experienced decompensation during lower-body negative pressure while breathing on a sham ITD. ${ }^{6}$ When that subject breathed through an active ITD with $7 \mathrm{~cm} \mathrm{H}_{2} \mathrm{O}$ inspiratory resistance at the same level of lower-body negative pressure, the relationship between arterial pressure and muscle sympathetic nerve activity oscillations was maintained at a high coherence (see Fig. 5, lower 3 panels). Those observations support the notion that optimizing the respiratory pump can maintain the coupling of autonomic oscillators and thereby delay the onset of hemodynamic decompensation from loss in central blood volume.

There is a growing body of experimental evidence from human subjects that supports the therapeutic use of the respiratory pump for the treatment of hypotension and central hypovolemia. Many of these studies were performed in collaboration with the National Aeronautics and Space Administration (NASA), as astronauts often suffer from 

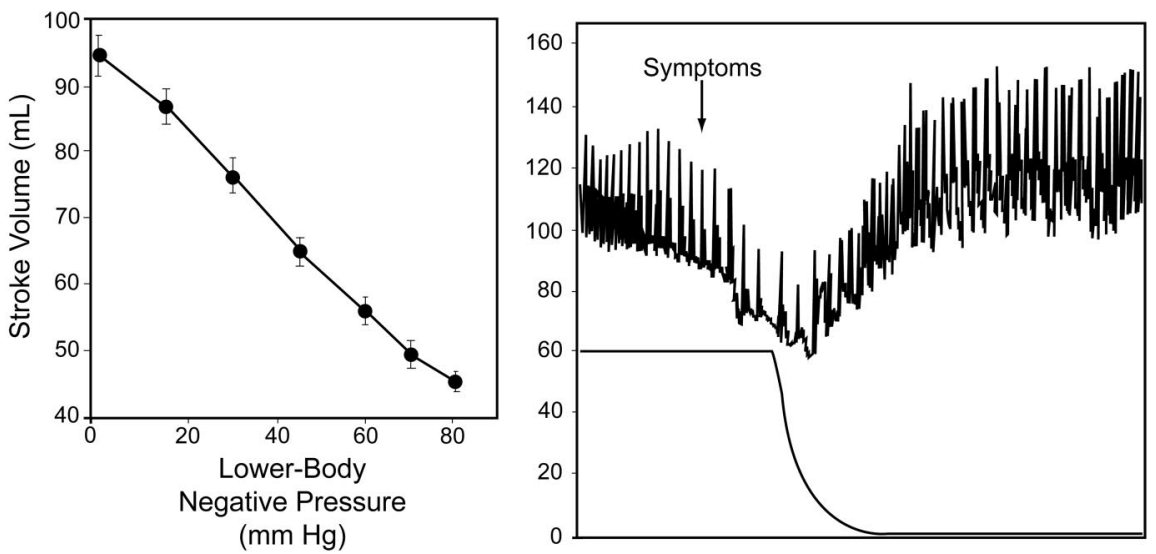

Fig. 4. Left: Stroke volume versus lower-body negative pressure in 20 human subjects. The data points represent the mean values. The error bars represent the standard error values. Right: Representative curve of beat-to-beat arterial blood pressure in a human during hemodynamic decompensation, at lower-body negative pressure of $60 \mathrm{~mm} \mathrm{Hg}$.
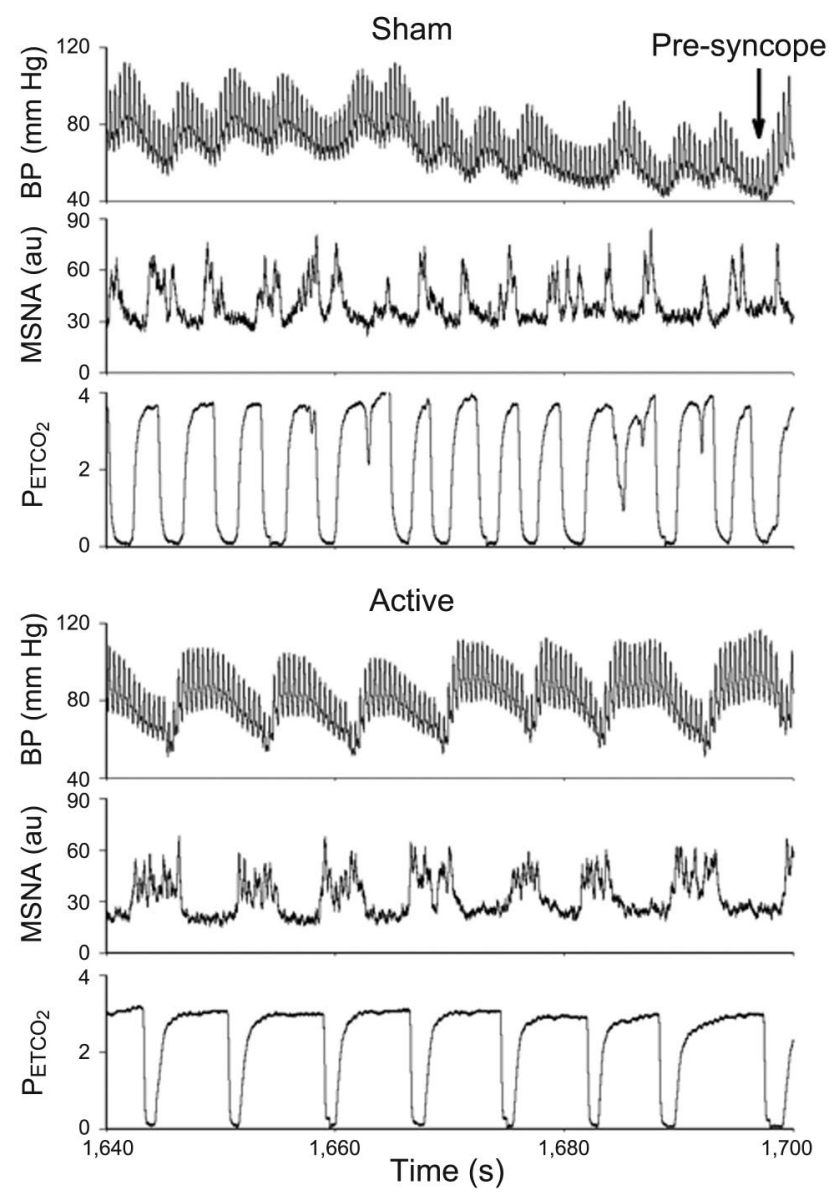

Fig. 5. Blood pressure (BP), muscle sympathetic nerve activity (MSNA), and end-tidal carbon dioxide $\left(\mathrm{P}_{\mathrm{ETCO}_{2}}\right)$ curves from a human breathing through a sham impedance threshold device (ITD) (upper 3 panels) and an active ITD (lower 3 panels). AU = arbitrary units. (Adapted from Reference 6.)

severe orthostatic hypotension following prolonged space flight and re-exposure to the earth's gravitational force.
Patient tolerance to inspiratory resistance and the respiratory pump's response to acute central hypovolemia induced by orthostasis and acute hemorrhage were studied in conjunction with NASA and the United States Army.

\section{Patient Tolerance and Response to Acute Central Hypovolemia Induced by Orthostasis}

To harness the respiratory pump clinically, initial studies were focused on tolerance to inspiratory resistance in normal human subjects. A series of studies were performed with normal subjects breathing through 2 different ITDs: one with a $7 \mathrm{~cm} \mathrm{H}_{2} \mathrm{O}$ pressure difference, and the other with a $12 \mathrm{~cm} \mathrm{H}_{2} \mathrm{O}$ pressure difference. The $7 \mathrm{~cm} \mathrm{H}_{2} \mathrm{O}$ pressure difference was well tolerated by all the healthy subjects, whereas subjects expressed difficulty completing protocols at $12 \mathrm{~cm} \mathrm{H}_{2} \mathrm{O} .{ }^{15}$ Tolerance of the $7 \mathrm{~cm} \mathrm{H}_{2} \mathrm{O}$ inspiratory pressure difference was reflected by a modest increase in the power of breathing ${ }^{20}$ without affecting respiratory frequency, tidal volume, or expired minute ventilation. ${ }^{14}$ Furthermore, the optimal benefits of inspiratory resistance were achieved with a minimal impedance, since improved hemodynamic responses were no greater at $12 \mathrm{~cm} \mathrm{H}_{2} \mathrm{O}$ than at $7 \mathrm{~cm} \mathrm{H}_{2} \mathrm{O} .{ }^{15}$

The next hypothesis tested was that inspiration through a low level of resistance provides short-term protection against hypotension associated with orthostatically induced central hypovolemia. Convertino et al therefore evaluated an ITD as a countermeasure against the development of orthostatic hypotension during the transient phase of a squat/stand test. ${ }^{17}$ Volunteers completed 2 counterbalanced protocols with and without an ITD set at $7 \mathrm{~cm} \mathrm{H}_{2} \mathrm{O}$. Heart rate, stroke volume, cardiac output, total peripheral resistance, and mean arterial pressure were measured during transition from squat to stand position. Subjective orthostatic symptoms were also recorded. The hypotension created during the transient phase of the squat/stand test was 

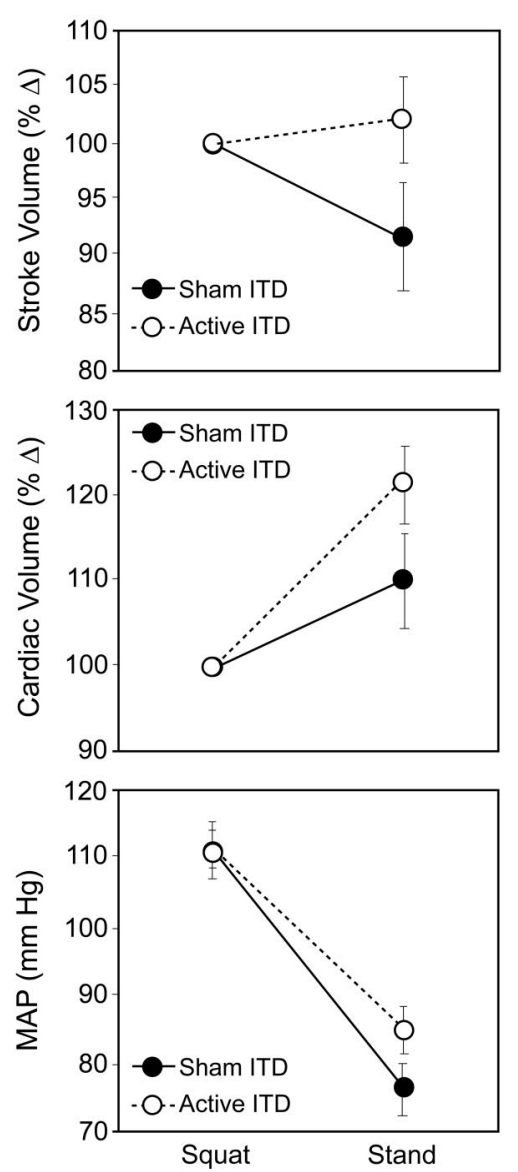

Fig. 6. Changes in stroke volume, cardiac output, and mean arterial blood pressure (MAP) in 18 human subjects during spontaneous breathing through an impedance threshold device (ITD), and a sham ITD. The data points represent the mean values. The error bars represent the standard error values. All the differences were statistically significant. (Adapted from Reference 17.)

attenuated with the active ITD and associated with higher stroke volume and cardiac output (Fig. 6). ${ }^{17}$ More clinically relevant was the reduction of orthostatic symptoms with an ITD, ${ }^{17}$ which demonstrates the ITD's potential therapeutic application as a countermeasure against orthostatic hypotension and consequent symptoms.

Since the creation of negative intrathoracic pressure ameliorated the adverse effects of central hypovolemia caused by the acute orthostatic challenge, the efficacy of optimizing the respiratory pump as a means for increasing tolerance to hemorrhage was investigated. ${ }^{13}$ Animal studies had previously demonstrated that an ITD increased mean arterial pressure in heat stroke, ${ }^{23}$ and blood pressure, ${ }^{24}$ cardiac output, ${ }^{25}$ and survival time ${ }^{26}$ after hypotension induced by severe blood loss. To determine if there were similar effects in humans, healthy subjects were exposed to progressive lower-body negative pressure. ${ }^{13}$ After an initial experiment to establish the subject's tolerance for lower-body negative pressure (ie, point of decompensa-

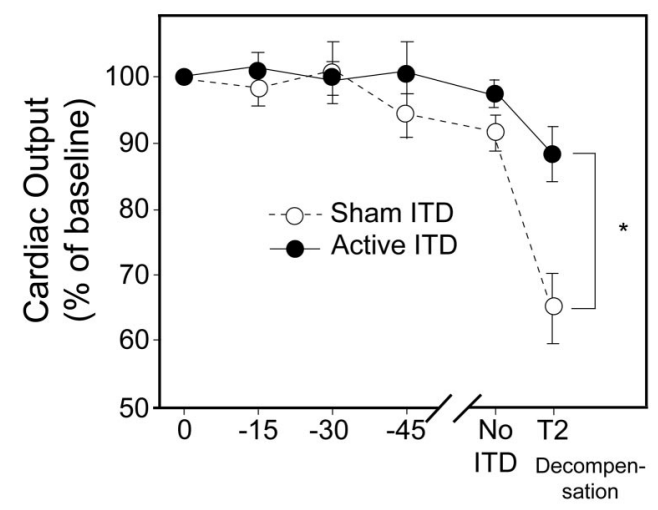

Fig. 7. Cardiac output versus lower-body negative pressure at the last stage of lower-body negative pressure before application of an impedance threshold device (ITD) or sham ITD. Between the 2 trials the values did not differ at lower-body-negative-pressure levels during which the subjects were not breathing through an ITD. * $P<.001$. (Adapted from Reference 6.)

tion), the subject underwent experimental sessions in which an ITD (randomized active or sham, with crossover) was used at one lower-body-negative-pressure level before the level that produced hemodynamic decompensation in the tolerance test. The subject breathed through the active ITD for an average of $15 \mathrm{~min}$ without difficulty.

The average systolic blood pressure at the time of hemodynamic decompensation was similar with the active and sham ITDs, ${ }^{13}$ but the mean systolic blood pressure was $40 \mathrm{~mm} \mathrm{Hg}$ higher with the active ITD at the time of hemodynamic decompensation $(102 \mathrm{~mm} \mathrm{Hg}$ vs $72 \mathrm{~mm} \mathrm{Hg}, P=.004)$. Higher systolic blood pressure with the active ITD was associated with greater cardiac output (Fig. 7) and a $12 \%(P=.006)$ increase in the average time to hemodynamic decompensation. In some subjects, the ITD extended the time to hemodynamic decompensation by $>10 \mathrm{~min}$. In other words, harnessing the respiratory pump in this human model of hemorrhage resulted in higher blood pressure and greater tolerance for a longer period of hemodynamic stress, which suggests that an ITD can "buy time" in the treatment of severe bleeding.

One of the most intriguing aspects of harnessing the respiratory pump is the interaction between changes in intrathoracic pressure and brain blood flow. The observation that inspiration through a low level of resistance was associated with delaying the onset of orthostatic intolerance symptoms ${ }^{17}$ was the basis for the hypothesis that the benefits of the enhanced respiratory pump might include improved cerebral perfusion. Although increased mean cerebral blood velocity was observed in human subjects breathing through an ITD set at $7 \mathrm{~cm} \mathrm{H}_{2} \mathrm{O}$ pressure difference in a human model of central hypovolemia, ${ }^{12}$ breathing through a low level of resistance unexpectedly failed to ameliorate the reduction in mean 


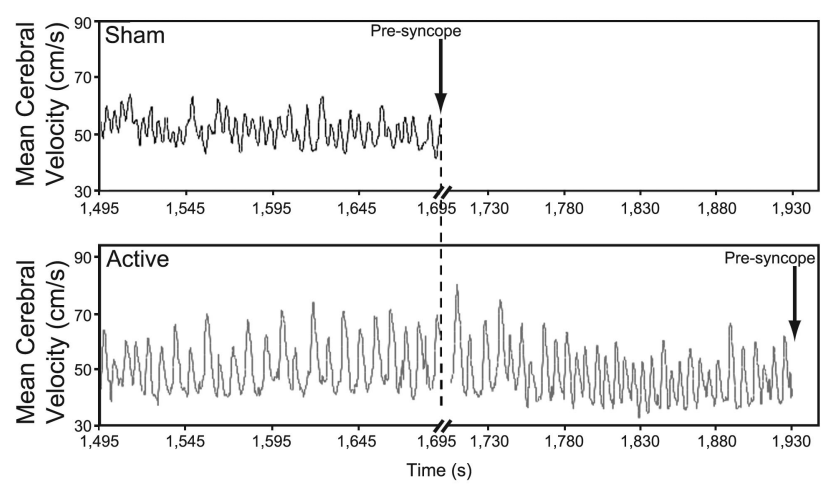

Fig. 8. Representative mean cerebral blood velocity oscillation curves from a human breathing through an impedance threshold device (ITD) or sham ITD. With the sham ITD, hemodynamic decompensation occurred at 1,695 s. In this example, cerebral blood velocity oscillations were analyzed immediately prior to $1,695 \mathrm{~s}$ for both trials, even though decompensation did not occur until 1,930 s with the active ITD. (Adapted from Reference 7.)

cerebral blood velocity. ${ }^{7,27}$ A novel finding, however, was a significant increase in the amplitude of cerebral blood velocity oscillations associated with inspiratory impedance breathing during reduced central blood volume. ${ }^{7,27}$ A recent preliminary examination of individual oscillatory waveforms also revealed a significant increase in the duration of each oscillation, so that oscillations occurred at a lower frequency during ITD breathing (Fig. 8). These alterations in oscillatory patterns may reflect a longer period of time for delivery of blood and oxygen to the brain. The delay in the onset of symptoms with the active ITD breathing might suggest that more sustained maximum velocities induced by enhanced negative intrathoracic pressure are a protective mechanism for maintaining adequate perfusion, which prolongs central nervous system tolerance to reduced central blood volume, even in the presence of hypotension. ${ }^{7,27}$

In addition to its effects on cerebral blood velocity dynamics, animal studies found that decreased intrathoracic pressure causes an immediate, proportionate reduction in intracranial pressure (Fig. 9). ${ }^{28}$ That suggests a remarkably high concordance between changes in intrathoracic pressure and intracranial pressure, which may have important implications in disorders that alter cerebral blood flow. Intracranial pressure increases cerebral perfusion pressure because the rigidity of the cranial vault creates a Starling resistor. Interestingly, the effect on intracranial pressure depends on the total blood volume: the lower the central blood volume, the lower the intrathoracic pressure becomes with each inspiration through an ITD. ${ }^{28}$ Maintaining adequate cerebral perfusion while reducing intracranial pressure could prove critical in prolonging or even preventing the progression to cerebral ischemia associated with cardiac arrest
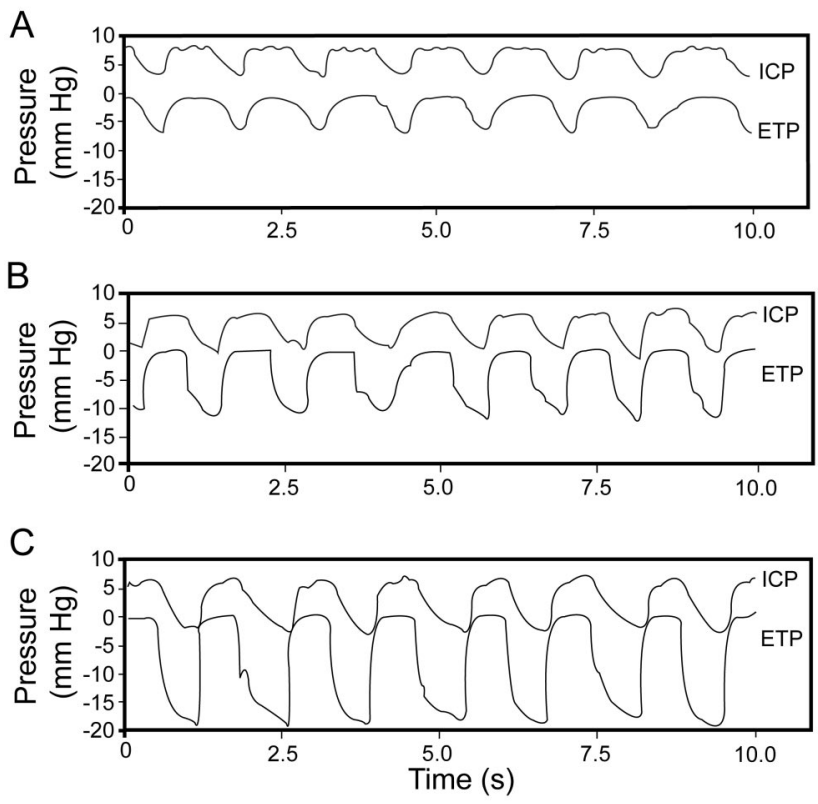

Fig. 9. Endotracheal pressure (ETP) and intracranial pressure (ICP) in a pig at (A) baseline, and while breathing through an impedance threshold device set for a cracking pressure of $(B)-10 \mathrm{~mm} \mathrm{Hg}$, or (C) $-15 \mathrm{~mm} \mathrm{Hg}$. (Adapted from Reference 28, with permission.)

and shock. We propose that the impact of this physiology underlies, in part, the delay in onset of symptoms in subjects using the ITD while undergoing progressive reduction in central blood volume that mimics hemorrhage. ${ }^{7}$ The multi-factorial effects of inspiration through a low level of resistance to harness the thoracic pump, and its consequent effect on cerebral perfusion, systemic circulation, and increased coherence between arterial blood pressure and sympathetic nerve activity improved survival rate in animals after severe hemorrhage. ${ }^{26}$ Although studies focused on survival in humans under similar conditions have not yet been performed, investigations in patients ${ }^{11}$ and research subjects $17,13,24$ have shown a hemodynamic benefit in the setting of clinically symptomatic hypotension, as described below.

\section{Potential Mechanisms of Action: Effects on Pressure Gradients That Determine Tissue Blood Flow}

In addition to increasing perfusion by "pushing" blood through tissues with higher cardiac output and systemic arterial pressure, an additional mechanism being investigated is whether inspiration through a low level of resistance also "pulls" blood through tissues. This is implied by the hemodynamic findings shown in Figure 1. Venous pressure is a key determinant of organ perfusion. By lowering intrathoracic pressure and, thus, 

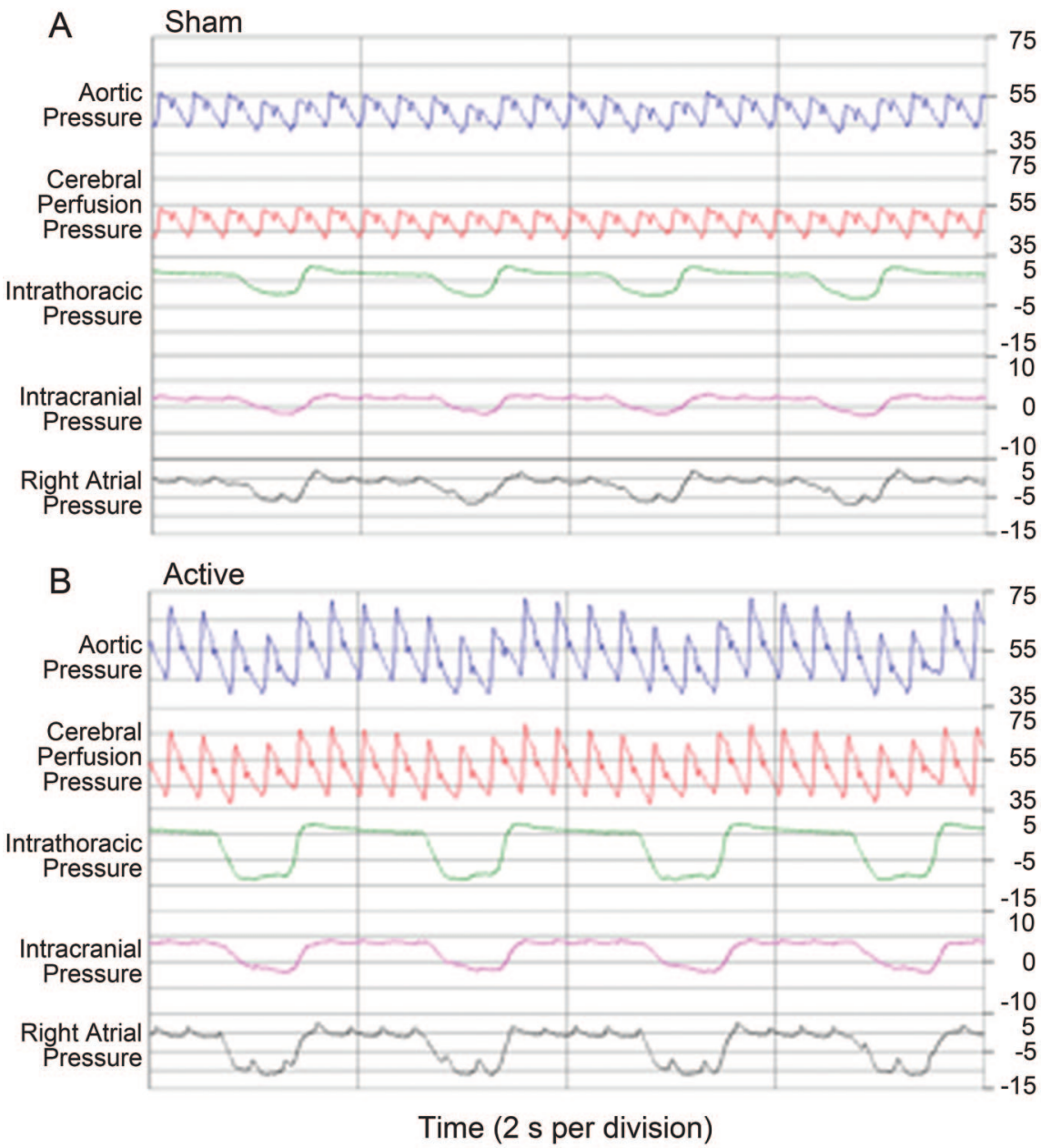

Fig. 10. Representative hemodynamic curves from a hypovolemic pig spontaneously breathing through an impedance threshold device (ITD, set for an inspiratory resistance $7 \mathrm{~cm} \mathrm{H}_{2} \mathrm{O}$ ), and a sham ITD. The cerebral perfusion pressure is the difference between the aortic pressure and the intracranial pressure. All pressure values are in $\mathrm{mm} \mathrm{Hg}$.

venous pressure, it is likely that inspiratory efforts that significantly lower intrathoracic pressure actually accelerate the passage of blood through capillary beds by a vacuum-generating effect in the thorax. Our observation that an ITD (set for a pressure difference of $7 \mathrm{~cm} \mathrm{H}_{2} \mathrm{O}$ ) increased cerebral blood velocity amplitude and duration (improved perfusion) and delayed symptom onset (improved organ function) despite the presence of relative hypotension is consistent with this notion. $^{7}$ These relationships led us to consider that the vacuum created by the respiratory pump causes a "waterfall" effect that increases blood flow by maximizing the pressure gradient across the circulation of vital organs.

Results from an animal hemorrhage model support the concept that reduced intrathoracic pressure lowers right-atrial pressure, which in turn pulls more venous blood back into the thorax. ${ }^{13,24}$ This hydraulic effect is illustrated in Figure 10, which shows representative re- cordings of the aortic, cerebral perfusion, intrathoracic, intracranial, and right-atrial pressures in an anesthetized pig with a fixed hemorrhage of $50 \%$ of calculated blood volume, while breathing through a sham ITD and an ITD set for a pressure difference of $7 \mathrm{~cm} \mathrm{H}_{2} \mathrm{O}$. In addition to the increased arterial pressure from the increased cardiac preload, the lower right-atrial pressure induced by the increased negative intrathoracic pressure may be instrumental in increasing the blood pressure gradient necessary to maintain adequate tissue perfusion. The data in Figure 10 also support a similar mechanism for enhanced cerebral perfusion. Based on these observations in the heart and brain, we hypothesize that resistance during inspiration enhances circulation in a more global manner in vital organs ${ }^{29,30}$ throughout the body, by increasing forward flow with elevated arterial pressure, and by active suction that pulls more blood through the capillary bed by a negative-pressure effect on reducing venous pressure. This "pull-through" mech- 
anism may be a new paradigm for hypotensive resuscitation and maintaining adequate tissue perfusion in the scenario of hemorrhage.

\section{Clinical Relevance of the Respiratory Pump}

\section{Outcomes From Clinical Applications}

Inspiratory resistance for the treatment of low-circulation states has been the subject of recent clinical studies. $5,8-10,19,31,32$ The most extensive experience is in the setting of CPR, where the intrathoracic pressure decrease is generated by chest-wall recoil during the CPR decompression phase, when the ITD prevents respiratory gas from entering the thorax except when a positive-pressure breath is delivered. In animals and patients in cardiac arrest and receiving standard CPR, enhancing the negative intrathoracic vacuum during the decompression phase with inspiratory resistance doubles blood flow to the heart and brain, ${ }^{33}$ doubles blood pressure in patients ${ }^{10}$ and doubles the likelihood of short-term, and in some cases long-term, survival. ${ }^{19,33-37}$ During CPR this benefit is further augmented when the chest is actively compressed and then actively decompressed with a suction-cup device. ${ }^{8}$ This active compression/decompression CPR method, together with a way to impede inspiration, provides 4 times the amount of blood flow to the heart and brain than does standard manual CPR. ${ }^{9,38,39}$ The cardiopulmonary interactions generated in this manner are similar to those in spontaneously breathing patients: each time the chest wall recoils, when respiratory gas is transiently blocked from entering the thorax, there is an immediate decrease in intrathoracic pressure, which enhances blood flow back to the heart and lowers intracranial pressure. ${ }^{28,34}$ Optimizing the thoracic pump during the compression and decompression phases of CPR increases vital organ blood flow, and more patients survive.

An ITD set at $7 \mathrm{~cm} \mathrm{H}_{2} \mathrm{O}$ was recently studied in spontaneously breathing patients with clinically symptomatic hypotension from multiple causes, including orthostatic hypotension secondary to autonomic dysfunction, ${ }^{11}$ blood donation, ${ }^{40}$ bleeding or dehydration, ${ }^{41}$ and renal dialysis. ${ }^{40}$ In all cases, resistance during inspiration helped the patients to treat themselves. In the emergency department and prehospital settings where patients are treated by paramedics, an ITD increased mean arterial pressure by an average of $10 \mathrm{~mm} \mathrm{Hg}$, in the absence of intravenous fluids. ${ }^{41}$

One version of the ITD is indicated for use in patients with low blood circulation. When used in cardiac arrest to augment circulation, positive-pressure ventilation should be delivered intermittently and the ITD should be removed upon return of spontaneous circulation. In patients who are spontaneously breathing and have symptomatic hypoten-
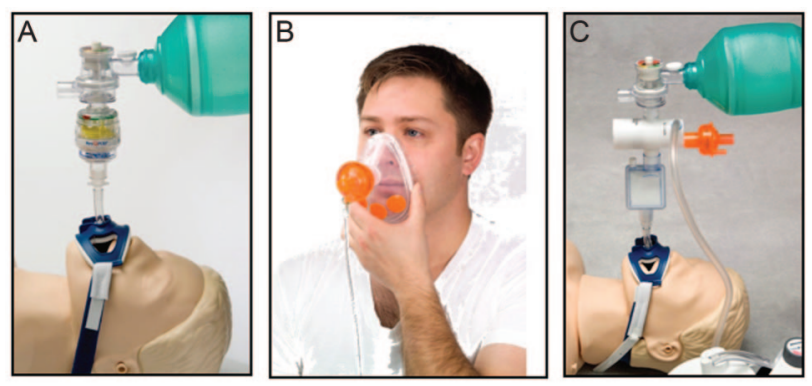

Fig. 11. A: ResQPOD impedance threshold device in a resuscitation bag circuit. B: ResQGARD in use by a spontaneously breathing patient. C: CirQLator in a resuscitation bag circuit. These devices have all been cleared by the Food and Drug Administration.

sion, an ITD should be removed once adequate blood circulation has been restored. Figure 11A shows how the ResQPOD ITD (Advanced Circulatory Systems, Roseville, Minnesota) is connected in the respiratory circuit in patients with cardiac arrest. Figure 11B shows how the ResQGARD (Advanced Circulatory Systems, Roseville, Minnesota) is used by a spontaneously breathing patient.

There are some limitations to the clinical use of the ITD. First, to use the ITD that is designed for spontaneously breathing patients (which has a fixed pressure difference of $7 \mathrm{~cm} \mathrm{H}_{2} \mathrm{O}$ ), the patient needs to be able to breathe spontaneously and without difficulty. Second, if a patient has difficulty breathing, then the additional work of breathing from the ITD can increase respiratory distress. Third, if the patient has heart failure and pulmonary edema, then augmenting blood flow to the heart with each inspiration could worsen the heart failure. Fourth, if the patient is bleeding, ITD application could accelerate the bleeding; however, there have been no animal or human studies that provide evidence to support this potential limitation.

\section{Future Directions}

The initial clinical case that indirectly inspired the concept of harnessing the respiratory pump to enhance circulation was a patient in cardiac arrest who was resuscitated with a common household plunger by family members. ${ }^{42}$ Blood moved from the heart to the brain when pushing downward on the chest, and air was drawn into the lungs when lifting upward. By delaying air entry into the lungs with inspiratory resistance, intrathoracic pressures became significantly more negative, which led to the re-discovery of "the other side of breathing." This mechanism can be further enhanced by another device, an intrathoracic pressure regulator (CirQlator, Advanced Circulatory Systems, Roseville, Minnesota, Figure 11C), which is used in hypotensive, non-breathing patients. The CirQlator is inserted between the patient and a ventilation source that allows delivery of a positive-pressure breath and then generates a 
Table 1. Clinical Uses of and Contraindications to the ResQPOD, ResQGARD, and CirQlator Inspiratory-Resistance Therapy Devices

\begin{tabular}{|c|c|c|c|}
\hline & $\begin{array}{c}\text { ResQPOD } \\
\text { (not for spontaneously } \\
\text { breathing patients) }\end{array}$ & $\begin{array}{c}\text { ResQGARD } \\
\text { (only for spontaneously } \\
\text { breathing patients) }\end{array}$ & $\begin{array}{c}\text { CirQlator } \\
\text { (not for spontaneously } \\
\text { breathing patients) }\end{array}$ \\
\hline \multicolumn{4}{|l|}{ Clinical Use } \\
\hline $\begin{array}{l}\text { Increase circulation during cardiopulmonary } \\
\text { resuscitation }\end{array}$ & $\mathrm{Yes}^{8-10,19,31,33-35 * 30,33,36-39 \dagger}$ & NA & Yes $^{43,45 \dagger}$ \\
\hline $\begin{array}{l}\text { Increase circulation in hypotension } \\
\text { secondary to hypovolemia (eg, blood } \\
\text { loss, renal dialysis) }\end{array}$ & NA & Yes $^{5,6,7,13,15,18,23,27,32,40,41 * 24-26 \dagger}$ & Yes $^{50,51 * 29,44,49 \dagger}$ \\
\hline $\begin{array}{l}\text { Increase circulation in hypotension } \\
\text { secondary to orthostatic hypotension }\end{array}$ & NA & Yes $^{11,16-18,40^{*}}$ & NA \\
\hline $\begin{array}{l}\text { Increase circulation in hypotension } \\
\text { secondary to sepsis }\end{array}$ & NA & Yes $^{5 *}$ & $\begin{array}{l}\text { Probably, but clinical data } \\
\text { currently lacking } 46 \dagger\end{array}$ \\
\hline $\begin{array}{l}\text { Increase circulation in hypotension } \\
\text { secondary to dehydration }\end{array}$ & NA & Yes $^{5 *}$ & $\begin{array}{l}\text { Probably, but clinical data } \\
\text { currently lacking }\end{array}$ \\
\hline $\begin{array}{l}\text { Increase circulation in hypotension } \\
\text { secondary to heat stroke }\end{array}$ & NA & $\begin{array}{l}\text { Probably, but clinical data } \\
\text { currently lacking } 23 \dagger\end{array}$ & NA \\
\hline $\begin{array}{l}\text { Decrease intracranial pressure (improve } \\
\text { cerebral perfusion pressure) }\end{array}$ & NA & Unknown & $\mathrm{Yes}^{52 * 28,47,48 \dagger}$ \\
\hline Uncontrolled ongoing bleeding & NA & $\begin{array}{l}\text { Probably, but clinical data } \\
\text { currently lacking } 26 \dagger\end{array}$ & Unknown \\
\hline \multicolumn{4}{|l|}{ Contraindications } \\
\hline Acute congestive heart failure & NA & Yes & Unknown \\
\hline Systemic hypertension & NA & Yes & $\begin{array}{l}\text { Probably, but clinical data } \\
\text { currently lacking }\end{array}$ \\
\hline Pulmonary hypertension & NA & Yes & Unknown \\
\hline Difficulty breathing (primary complaint) & NA & Yes & NA \\
\hline Spontaneously breathing & Yes & NA & Yes \\
\hline Acute lung injury & NA & Yes & Yes \\
\hline Penetrating chest trauma & Yes & Yes & Yes \\
\hline Hypoxemia despite supplemental oxygen & NA & Yes & Unknown \\
\hline \multicolumn{4}{|l|}{ Discontinuation of Use Criteria } \\
\hline Return of spontaneous circulation & Yes & NA & NA \\
\hline $\begin{array}{l}\text { Stable blood pressure and primary cause of } \\
\text { hypotension reversed }\end{array}$ & Yes & Yes & Yes \\
\hline $\begin{array}{l}\text { Resumption of spontaneous normal } \\
\text { breathing }\end{array}$ & Yes & NA & Yes \\
\hline $\begin{array}{l}\text { Clinical studies } \\
\dagger \text { Animal studies } \\
\mathrm{NA}=\text { not applicable }\end{array}$ & & & \\
\hline
\end{tabular}

continuous low-level sub-atmospheric pressure of up to $-12 \mathrm{~cm} \mathrm{H}_{2} \mathrm{O}$ by the active extraction of respiratory gas between positive-pressure ventilations. Inside the CirQlator is a piston that allows for unrestricted positive-pressure ventilation from an external source (ventilator or resuscitator bag). The piston closes immediately at the end of the positive-pressure breath, and the patient airway is subjected to a low level of negative pressure generated by an external vacuum source, which is regulated to a specific resistance by a one-way check valve. With the CirQlator, the decrease in intrathoracic pressure after each positivepressure breath enhances venous blood flow to the heart, lowers intracranial pressure, and raises systemic arterial pressure, cardiac stroke volume, and cerebral perfusion pressure. In animals the CirQlator was of significant benefit in CPR after cardiac arrest, hemorrhagic shock, elevated intracranial pressure from traumatic brain injury, septic shock, and combined hemorrhagic shock and cardiac arrest. ${ }^{28,29,43-49}$ As with the ResQPOD and ResQGard, we speculate that the CirQlator both "pushes" and "pulls" blood through the capillary bed, thereby providing a novel and important new tool to enhance circulation in poorperfusion states secondary to hypovolemia. The CirQlator has been used clinically in patients with normal pulmonary function and with intraoperative hypotension and found to consistently increase pulse pressure and systemic blood pressure. ${ }^{50}$ In addition, transesophageal echocardiographic studies in coronary-artery-bypass patients found that the 


\section{Harnessing Inspiratory Resistance to Treat Systemic Hypotension}

CirQlator consistently increased cardiac output by about $1 \mathrm{~L} / \mathrm{min}$, similar to what was observed in animals. ${ }^{51}$ More recently, the CirQlator was used to lower intracranial pressure in patients with head injury. ${ }^{52}$

It is possible that this approach cannot be used in patients with acute lung injury, COPD, or with substantial hypoxemia, without the addition of PEEP after a period of expiratory-phase negative intrathoracic pressure. Studies of this 3-phase approach (positive intrathoracic pressure to deliver a breath, negative intrathoracic pressure to enhance circulation, and PEEP to prevent atelectasis) are underway.

The potential therapeutic implications for harnessing the thoracic pump to treat patients with poly-trauma who suffer combined traumatic brain injury and blood volume loss secondary to hemorrhage are substantial. Currently, the dominant therapeutic paradigm for the critical care management of such patients is the maintenance of a cerebral perfusion pressure adequate to prevent secondary brain injury. As cerebral perfusion pressure is calculated by subtracting the intracranial pressure from the mean arterial pressure, it can be readily appreciated that a treatment modality that preserves mean arterial pressure and lowers intracranial pressure would lend substantial advantage in such patients. The theoretical neuroprotective benefits of cerebral blood velocity oscillations in brain-injured patients, who have lost the capacity for cerebral blood flow autoregulation, are additionally compelling. Finally, the cerebral and systemic resuscitative advantages of inspiratory-resistance therapy avoid the potential burdens of crystalloid infusion, including hemodilution, coagulopathy, cerebral edema, and compartment syndrome. Table 1 summarizes the clinical conditions that inspiratory-resistance therapy may benefit, as well as the contraindications.

\section{Summary}

A common mechanism of mortality in cardiac arrest or hemorrhage is inadequate cardiac filling, so any therapy that increases venous return should decrease mortality. Increased negative intrathoracic pressure during spontaneous inspiration has been recognized for more than 50 years as a natural mechanism for enhancing venous return and cardiac filling. ${ }^{4,53}$ The Müller maneuver is one of several natural ways to enhance central blood volume and thus automatically increase cardiac output and blood pressure. A more common and normal physiological countermeasure to central hypovolemia is the simple act of taking deep breaths. Repetitive deep inspirations are induced by exercise and by cardiovascular stress, and are part of the body's most basic physiological response system; each deep inspiration is associated with many of the same physiological effects as gasping. Taking advantage of these fundamental relationships between respiratory, cardiovas- cular, and cerebrovascular physiologies, it is possible to harness these natural processes and to create a greater vacuum within the thorax during each spontaneous inspiration, and consequently to enhance venous return and preload to the heart. While the ITD technology was originally designed as an adjunct to CPR, it has become a useful research and clinical tool to enhance circulation during normal breathing, particularly during hypotension secondary to central hypovolemia. This approach provides new tools for respiratory therapists and pulmonologists to help treat cardiovascular collapse by utilizing "the other side of breathing."

\section{ACKNOWLEDGMENTS}

We thank Gary Muniz and Scott McKnite for technical assistance, and John McManus MD for assistance with the physical examinations and monitoring the subjects.

\section{REFERENCES}

1. Bobrow BJ, Zuercher M, Ewy GA, Clark L, Chikani V, Donahue D, et al. Gasping during cardiac arrest in humans is frequent and associated with improved survival. Circulation 2008;118(24):2550-2254.

2. Kentsch M, Stendel M, Berkel H, Mueller-Esch G. Early prediction of prognosis in out-of-hospital cardiac arrest. Intensive Care Med 1990;16(6):378-383.

3. Mullie A, Lewi P, Van Hoeyweghen R; Cerebral Resuscitation Study Group. Pre-CPR conditions and the final outcome of CPR. Resuscitation 1989;17(Suppl):S11-S21; discussion S199-S206.

4. Moreno AH, Burchell AR, Van der Woude R, Burke JH. Respiratory regulation of splanchnic and systemic venous return. Am J Physiol 1967;213(2):455-465.

5. Smith S, Metzger A, Kopitzke J, Clinton J, Lurie K. An impedance threshold device increases blood pressure in hypotensive patients. J Emerg Med 2010; [Epub ahead of print].

6. Ryan KL, Cooke WH, Rickards CA, Lurie KG, Convertino VA. Breathing through an inspiratory threshold device improves stroke volume during central hypovolemia in humans. J Appl Physiol 2008; 104(5):1402-1409.

7. Rickards CA, Ryan KL, Cooke WH, Lurie KG, Convertino VA. Inspiratory resistance delays the reporting of symptoms with central hypovolemia: association with cerebral blood flow. Am J Physiol Regul Integr Comp Physiol 2007;293(1):R243-R250.

8. Plaisance P, Lurie KG, Vicaut E, Martin D, Gueugniaud PY, Petit JL, Payen D. Evaluation of an impedance threshold device in patients receiving active compression-decompression cardiopulmonary resuscitation for out of hospital cardiac arrest. Resuscitation 2004; 61(3):265-271.

9. Plaisance P, Lurie KG, Payen D. Inspiratory impedance during active compression-decompression cardiopulmonary resuscitation: a randomized evaluation in patients in cardiac arrest. Circulation 2000; 101(9):989-994.

10. Pirrallo RG, Aufderheide TP, Provo TA, Lurie KG. Effect of an inspiratory impedance threshold device on hemodynamics during conventional manual cardiopulmonary resuscitation. Resuscitation 2005;66(1):13-20.

11. Melby DP, Lu F, Sakaguchi S, Zook M, Benditt DG. Increased impedance to inspiration ameliorates hemodynamic changes associated with movement to upright posture in orthostatic hypotension: a randomized blinded pilot study. Heart Rhythm 2007;4(2):128-135. 


\section{Harnessing Inspiratory Resistance to Treat Systemic Hypotension}

12. Cooke WH, Lurie KG, Rohrer MJ, Convertino VA. Human autonomic and cerebrovascular responses to inspiratory impedance. J Trauma 2006;60(6):1275-1283.

13. Convertino VA, Ryan KL, Rickards CA, Cooke WH, Idris AH, Metzger A, et al. Inspiratory resistance maintains arterial pressure during central hypovolemia: Implications for treatment of patients with severe hemorrhage. Crit Care Med 2007;35(4):1145-1152.

14. Convertino VA, Ratliff DA, Ryan KL, Doerr DF, Ludwig DA, Muniz GW, et al. Hemodynamics associated with breathing through an inspiratory impedance threshold device in human volunteers. Crit Care Med 2004;32(9 Suppl):S381-S386.

15. Convertino VA, Ratliff DA, Ryan KL, Cooke WH, Doerr DF, Ludwig DA, et al. Effects of inspiratory impedance on the carotidcardiac baroreflex response in humans. Clin Auton Res 2004;14(4): 240-248.

16. Convertino VA, Ratliff DA, Eisenhower KC, Warren C, Doerr DF, Idris AH, Lurie KG. Inspiratory impedance effects on hemodynamic responses to orthostasis in normal subjects. Aviat Space Environ Med 2006;77(5):486-493.

17. Convertino VA, Ratliff DA, Crissey J, Doerr DF, Idris AH, Lurie KG. Effects of inspiratory impedance on hemodynamic responses to a squat-stand test in human volunteers: implications for treatment of orthostatic hypotension. Eur J Appl Physiol 2005;94(4):392-399.

18. Convertino VA, Cooke WH, Lurie KG. Inspiratory resistance as a potential treatment for orthostatic intolerance and hemorrhagic shock. Aviat Space Environ Med 2005;76(4):319-325.

19. Aufderheide TP, Pirrallo RG, Provo TA, Lurie KG. Clinical evaluation of an inspiratory impedance threshold device during standard cardiopulmonary resuscitation in patients with out-of-hospital cardiac arrest. Crit Care Med 2005;33(4):734-740.

20. Idris AH, Convertino VA, Ratliff DA, Doerr DF, Lurie KG, Gabrielli A, Banner MJ. Imposed power of breathing associated with use of an impedance threshold device. Respir Care 2007;52(2):177-183.

21. Cooke WH, Ryan KL, Convertino VA. Lower body negative pressure as a model to study progression to acute hemorrhagic shock in humans. J Appl Physiol 2004;96(4):1249-1261.

22. Cooke WH, Rickards CA, Ryan KL, Kuusela TA, Convertino VA. Muscle sympathetic nerve activity during intense lower body negative pressure to presyncope in humans. J Physiol 2009;587(Pt 20): 4987-4999.

23. Voelckel W, Yannopoulos D, Zielinski T, McKnite S, Lurie KG. Inspiratory impedance threshold device effects on hypotension in heat-stroked swine. Aviat Space Environ Med 2008;79(8):743-748.

24. Lurie KG, Zielinski TM, McKnite SH, Idris AH, Yannopoulos D, Raedler CM, et al. Treatment of hypotension in pigs with an inspiratory impedance threshold device: a feasibility study. Crit Care Med 2004;32(7):1555-1562.

25. Marino BS, Yannopoulos D, Sigurdsson G, Lai L, Cho C, Redington $\mathrm{A}$, et al. Spontaneous breathing through an inspiratory impedance threshold device augments cardiac index and stroke volume index in a pediatric porcine model of hemorrhagic hypovolemia. Crit Care Med 2004;32(9 Suppl):S398-S405.

26. Sigurdsson G, Yannopoulos D, McKnite SH, Sondeen JL, Benditt DG, Lurie KG. Effects of an inspiratory impedance threshold device on blood pressure and short term survival in spontaneously breathing hypovolemic pigs. Resuscitation 2006;68(3):399-404.

27. Rickards CA, Cohen KD, Bergeron LL, Burton L, Khatri PJ, Lee $\mathrm{CT}$, et al. Inspiratory resistance, cerebral blood flow velocity, and symptoms of acute hypotension. Aviat Space Environ Med 2008; 79(6):557-564.

28. Yannopoulos D, McKnite SH, Metzger A, Lurie KG. Intrathoracic pressure regulation for intracranial pressure management in normovolemic and hypovolemic pigs. Crit Care Med 2006;34(12 Suppl): S495-S500.
29. Yannopoulos D, Metzger A, McKnite S, Nadkarni V, Aufderheide $\mathrm{TP}$, Idris A, et al. Intrathoracic pressure regulation improves vital organ perfusion pressures in normovolemic and hypovolemic pigs. Resuscitation 2006;70(3):445-453.

30. Aufderheide TP, Lurie KG. Vital organ blood flow with the impedance threshold device. Crit Care Med 2006;34(12 Suppl):S466S473.

31. Wolcke BB, Mauer DK, Schoefmann MF, Teichmann H, Provo TA, Lindner KH, et al. Comparison of standard cardiopulmonary resuscitation versus the combination of active compression-decompression cardiopulmonary resuscitation and an inspiratory impedance threshold device for out-of-hospital cardiac arrest. Circulation 2003;108(18):2201-2205.

32. Lindstrom DA, Parquette BA. Use of an impedance threshold device increases blood pressure in spontaneously breathing hypotensive patients. Prehosp Emerg Care 2009;13(1):99-100.

33. Lurie KG, Voelckel WG, Zielinski T, McKnite S, Lindstrom P, Peterson $\mathrm{C}$, et al. Improving standard cardiopulmonary resuscitation with an inspiratory impedance threshold valve in a porcine model of cardiac arrest. Anesth Analg 2001;93(3):649-655.

34. Aufderheide TP, Alexander C, Lick C, Myers B, Romig L, Vartanian $\mathrm{L}$, et al. From laboratory science to six emergency medical services systems: new understanding of the physiology of cardiopulmonary resuscitation increases survival rates after cardiac arrest. Crit Care Med 2008;36(Suppl):S397-S404.

35. Thigpen K, Davis S, Basol R, Lange P, Jain S, Olsen J, et al. Implementing the 2005 AHA guidelines including use of the impedance threshold device improves hospital discharge rates after inhospital cardiac arrest. Respir Care 2010:55(8):1014-1019.

36. Lurie KG, Zielinski T, McKnite S, Aufderheide T, Voelckel W. Use of an inspiratory impedance valve improves neurologically intact survival in a porcine model of ventricular fibrillation. Circulation 2002;105(1):124-129.

37. Yannopoulos D, Sigurdsson G, McKnite S, Benditt D, Lurie KG. Reducing ventilation frequency combined with an inspiratory impedance device improves CPR efficiency in swine model of cardiac arrest. Resuscitation 2004;61(1):75-82.

38. Lurie KG, Coffeen P, Shultz J, McKnite S, Detloff B, Mulligan K. Improving active compression-decompression cardiopulmonary resuscitation with an inspiratory impedance valve. Circulation 1995; 91(6):1629-1632

39. Lurie KG, Lindner KH. Recent advances in cardiopulmonary resuscitation. J Cardiovasc Electrophysiol 1997;8(5):584-600.

40. Convertino VA, Cooke WH, Lurie KG. Restoration of central blood volume: application of a simple concept and simple device to counteract cardiovascular instability in syncope and hemorrhage. J Gravitat Physiol 2005;12(1):P55-P60.

41. Parsons D, Convertino VA, Idris AH, Smith S, Lindstrom D, Parquette B, Aufderheide T. The impedance threshold device (ITD-7): a new device for combat casualty care to augment circulation and blood pressure in hypotensive spontaneously breathing war fighters. J Spec Oper Med 2009;9(2):49-52.

42. Lurie KG, Lindo C, Chin J. CPR: the P stands for plumber's helper. JAMA 1990;264(13):1661.

43. Yannopoulos D, Nadkarni VM, McKnite SH, Rao A, Kruger K, Metzger A, et al. Intrathoracic pressure regulator during continuouschest-compression advanced cardiac resuscitation improves vital organ perfusion pressures in a porcine model of cardiac arrest. Circulation 2005;112(6):803-811.

44. Yannopoulos D, McKnite S, Metzger A, Lurie KG. Intrathoracic pressure regulation improves 24-hour survival in a porcine model of hypovolemic shock. Anesth Analg 2007;104(1):157-162. 


\section{Harnessing Inspiratory Resistance to Treat Systemic Hypotension}

45. Yannopoulos D, Aufderheide TP, McKnite S, Kotsifas K, Charris R, Nadkarni V, Lurie KG. Hemodynamic and respiratory effects of negative tracheal pressure during CPR in pigs. Resuscitation 2006; 69(3):487-494.

46. Cinel I, Goldfarb R, Carcasses A, Jasti P-C, Knob C, Parrillo J, et al. Intrathoracic pressure regulation augments cardiac index in porcine peritonitis (abstract). Crit Care Med 2008;36(12 Suppl)A6.

47. Metzger A, Matsuura T, McKnite S, Lurie K. The intrathoracic pressure regulator improves cerebral perfusion pressures and carotid blood flow in a porcine model of traumatic brain injury. Circulation 2008;118(Suppl):664.

48. Kwon Y, Metzger A, Matsuura T, McKnite S, Yannopoulos D, Lurie $\mathrm{K}$. Prolonged treatment with the intrathoracic pressure regulator improves cerebral perfusion pressure and decreases intracranial pressure without compromising lung function in a porcine model of traumatic brain injury. Neurocrit Care 2010;13(Suppl):S183.
49. Metzger A, Matsuura T, McKnite S, Marino B, Nadkarni V, Lurie K, Yannopoulos D. The intrathoracic pressure regulator improves hemodynamics and 24-hour survival in a pediatric porcine model of severe hemorrhagic shock. Circulation 2010.

50. Birch M, Beebe D, Kwon Y, Loushin M, Belani K, Castro C, et al. A novel intrathoracic pressure regulator improves hemodynamics in hypotensive patients during surgery. Circulation 2010.

51. Huffmyer J, Groves D, DeSouza D, Littlewood K, Thiele R, Nemergut $\mathrm{E}$. The effect of the intrathoracic pressure regulator on hemodynamics and cardiac output. Shock 2011;35(2):114-116.

52. Nemergut E, Thiele R, Kiehna E, Huffmyer J, Scalzo D. The intrathoracic pressure regulator to lower ICP in patients with altered intracranial elastance. San Diego: October 16, 2010:A209.

53. Guyton AC, Lindsey AW, Abernathy B, Richardson T. Venous return at various right atrial pressures and the normal venous return curve. Am J Physiol 1957;189(3):609-615. 